\title{
Nucleolin from Xenopus laevis: cDNA cloning and expression during development
}

\author{
Michèle Caizergues-Ferrer, ${ }^{1}$ Paolo Mariottini, ${ }^{2}$ Catherine Curie, ${ }^{1}$ Bruno Lapeyre, ${ }^{1}$ Nicole Gas, ${ }^{1}$ \\ François Amalric, ${ }^{1}$ and Francesco Amaldi ${ }^{2}$ \\ ${ }^{1}$ Centre de Recherche de Biochimie et de Génétique Cellulaires du CNRS, 31062 Toulouse Cédex, France ${ }^{2}$ Dipartimento di \\ Biologia, II Università di Roma 'Tor Vergata,' 00173 Rome, Italy
}

\begin{abstract}
Nucleolin is a key nucleolar protein in higher eukaryotic cells and is involved directly in ribosome biogenesis. Using an antiserum raised against hamster nucleolin, the homologous protein was detected in nucleoli of Xenopus laevis hepatocytes as well as in the amplified nucleoli of oocytes. A cDNA encoding Xenopus nucleolin has been isolated and sequenced. The deduced protein sequence reveals similar domains in Xenopus and in mammals, but they have undergone separate evolutions. In particular, each of the four RNA-binding domains has evolved differently-the carboxy-proximal domain is twice as conserved $(87 \%)$ as the aminoproximal domain $(42 \%)$. These data shed some light on the possible roles of each domain. The expression of nucleolin has been followed throughout oogenesis and embryogenesis. The appearance of nucleolin during early development precedes the transcription of rDNA and the synthesis of ribosomal proteins. The maximal accumulation of nucleolin at gastrulation coincides with nucleolar reformation. Furthermore, when ribosomal synthesis is activated during oogenesis and embryogenesis, peptides immunorelated to nucleolin appear and accumulate. The results suggest that nucleolin plays a role not only in ribosome assembly but also in nucleologenesis.
\end{abstract}

[Key Words: Ribosome biogenesis; nucleologenesis; nucleolar proteins; RNA-binding domain; oogenesis; embryogenesis]

Received November 21, 1988; revised version accepted December 28, 1988.

Ribosome biosynthesis, whose main steps occur in the nucleolus of higher eukaryotic cells, requires the coordinate expression of $>100$ genes. Not only is the transcription of these genes carried out by three different RNA polymerases, but different post-transcriptional events are also involved. Some RNAs undergo a maturation process within the nucleolus, while other transcripts need to be spliced, exported to the cytoplasm, and translated into proteins which are then transported to the nucleolus. There are many different levels at which controls could be exerted (for review, see Hadjiolov 1985). Until now, attempts to find a common regulatory trigger that could explain the coordinate expression of these genes have been unsuccessful.

Nucleolin is a major nucleolar protein that is ubiquitous to higher vertebrates (Orrick et al. 1973; Pfeifle and Anderer 1983; Sapp et al. 1986). The amount of nucleolin in the cell is correlated directly with nucleolar transcriptional activity (Escande-Géraud et al. 1985; Bouche et al. 1987). It has been shown to be associated with pre-rRNA (Bugler et al. 1987), chromatin (Olson and Thompson 1983; Erard et al. 1988), preribosomes (Bugler et al. 1982; Herrera and Olson 1986), and the nucleolar matrix (Caizergues-Ferrer et al. 1984) and could play a role in the organization of nucleolar substructure.
The complete sequence of the Chinese hamster protein has been established (Lapeyre et al. 1987), and more recently, the gene encoding nucleolin was isolated and characterized in rodents (Bourbon et al. 1988a). The sequence reveals several interesting features including a striking array of four RNA-binding domains.

We were interested in studying the pattern of expression of nucleolin to get an insight on the regulation of ribosome biogenesis. For such an investigation, Xenopus laevis is a useful model system due to the existence of two developmental situations in which ribosome synthesis represents a major effort of the cell: (1) following rDNA amplification in oogenesis, when a huge amount of ribosomes is produced from the amplified nucleoli and stored for use during early development; and $(2)$ in embryogenesis, when the maternal stock of ribosomes is used up and the embryo begins to synthesize new ones. The relative timing of expression for rRNA, 5S RNA, and ribosomal proteins is well documented in Xenopus development (for review, see Davidson 1986). The reformation of nucleoli beginning in gastrula is correlated with a weak revival of rDNA transcription (Busby and Reeder 1982) and a slow recovery of ribosomal protein synthesis (Pierandrei-Amaldi et al. 1982). Because in mammalian cells, at the end of mitosis, nucleolin is 

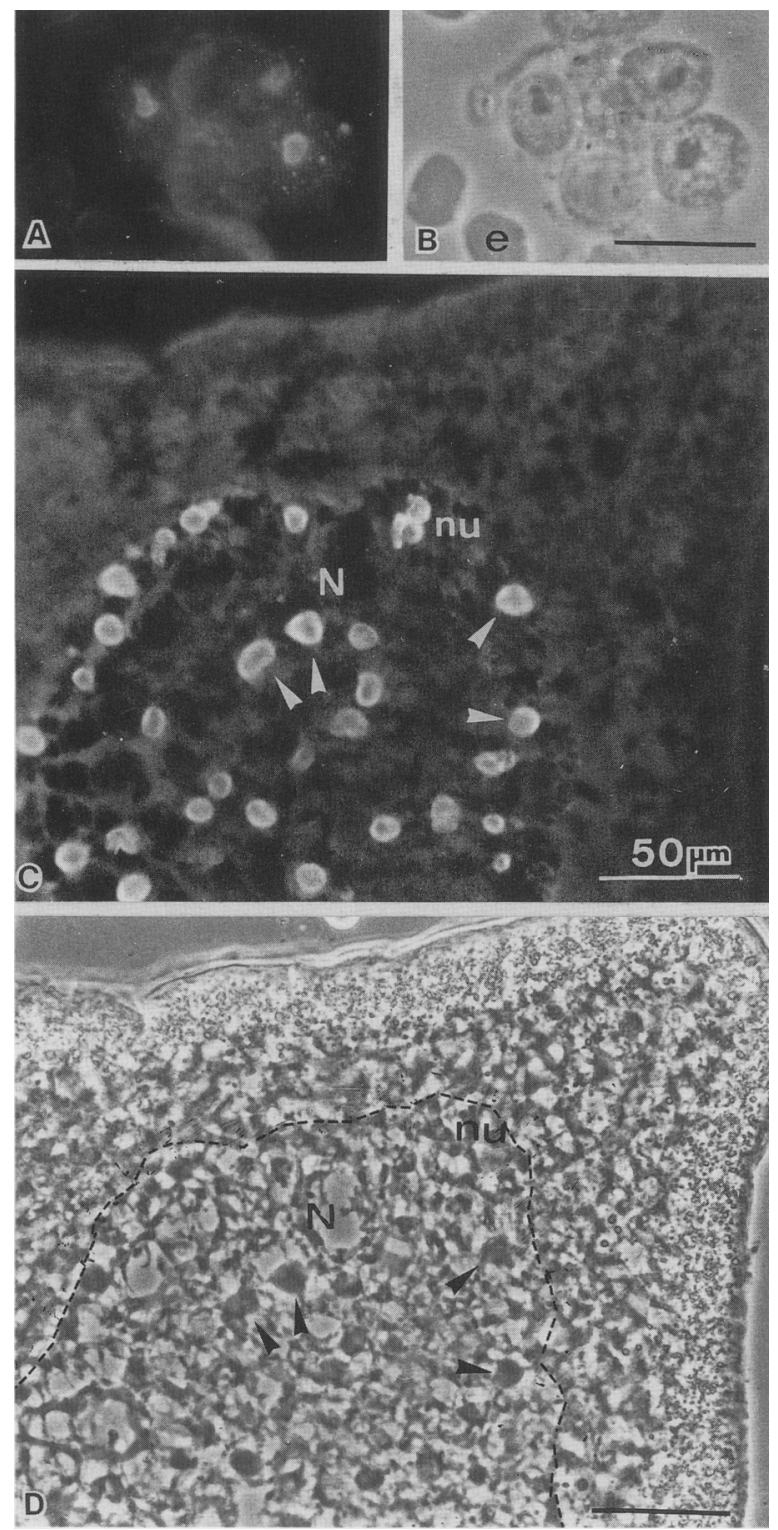

Figure 1. Nucleolin localization. Indirect immunofluorescence microscopy on isolated liver nuclei from Xenopus using the purified antiserum raised against $\mathrm{CHO}$ nucleolin $(A)$ and corresponding phase contrast $(B)$. Nucleoli are stained positively. Erythrocytes are not stained $(e)$. Frozen section of Xenopus ovary $(C)$ showing part of an oocyte nucleus $(N)$ with numerous nucleoli after incubation with anti-nucleolin antibody. The amplified nucleoli (nu) at this stage (st. IV) are strongly fluorescent. $(D)$ Phase contrast: the nucleus is circled. Bar, $50 \mu \mathrm{m}$.

shown to be present in the prenucleolar bodies that participate in nucleolar reformation (Gas et al. 1985; Ochs et al. 1985) and is thus involved in early events of nucleolar function, we wanted to follow the fate of the maternal nucleolin in Xenopus oocytes and the expression of nucleolin during embryogenesis. In addition, elucidation of the structure of nucleolin from Xenopus would allow us to compare the sequence of this protein in an amphibian with that in rodents.
We report here the isolation and sequence of a cDNA clone encoding $X$. laevis nucleolin. Despite the similarity of these homologous proteins, our data indicate that certain domains of the protein have undergone a different evolution in Xenopus and in mammals. We have made use of the cDNA clone to study the expression nucleolin throughout Xenopus oogenesis and embryogenesis.

\section{Results \\ Detection and characterization of $\mathrm{X}$. laevis nucleolin and its $m R N A$}

IgG purified from a rabbit polyclonal antiserum raised against hamster nucleolin was used to identify nucleolin by immunofluorescence in Xenopus hepatocytes and oocytes (Fig. 1). Fluorescent staining was seen in hepatocyte nucleoli and in all amplified oocyte nucleoli. The same antiserum was used to detect the reactive protein by Western blot analysis (Fig. 2). On purified hepatocyte nuclear proteins, the antiserum recognized two polypeptides of $M_{\mathrm{r}} 95,000$ and 90,000 and gave a weak reaction with two others of $M_{r} 59,000$ and 48,000 (Fig. 2, lane 2). In Xenopus ooctes from stages I to III (according to Dumont 1972), the antiserum reacted with two polypeptides of $M_{r} 95,000$ and $M_{r} 90,000$, as in somatic cells, but

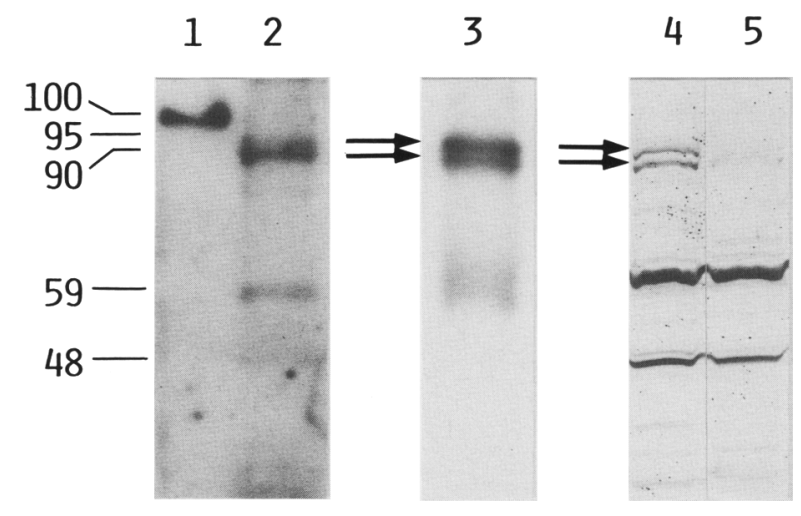

Figure 2. Detection of nucleolin in $X$. laevis. Protein analysis. (Lanes 1, 2, 4, and 5) Protein extracts separated on a 10\% SDSPAGE and electroblotted were probed using an antiserum raised against $\mathrm{CHO}$ nucleolin. Detection of the complexes was achieved either by ${ }^{125}$ I-labeled protein $\mathrm{A}$ (lanes 1 and 2), or by a second antiserum coupled to alkaline phosphatase (lanes 4 and 5). (Lane 3) Protein phosphorylation was obtained with an endogenous kinase contained in a low-ionic-strength extract of Xenopus hepatocyte nuclei and addition of $\left[\gamma^{-32} \mathrm{P}\right]$ ATP. Proteins were separated as before, then the gel was dried and autoradiographed for $4 \mathrm{hr}$ at $-70^{\circ} \mathrm{C}$ with an intensifying screen. (Lane 1) As a control, $0.2 \mu \mathrm{g}$ of nucleolin purified from $\mathrm{CHO}$ cells was run in parallel. (Lane 2) Low-ionic-strength extract from nuclei of Xenopus hepatocytes. (Lane 4) Protein extract corresponding to 10 oocytes from stage I to III, roughly separated from the yolk (see Materials and methods). (Lane 5) Same as in lane 4, but with oocytes from stage IV to VI. Numbers on the left refer to the molecular weight of the peptides, in $\mathrm{kD}$. 
gave only a slight reaction whereas a strong signal was obtained for the two smaller polypeptides (Fig. 2, lane 4). In oocytes from stages IV to VI only these last two polypeptides were observed (Fig. 2, lane 5).

In earlier studies we have shown that a low ionic strength extract of nuclei isolated from Chinese Hamster Ovary (CHO) cells contains a type NII protein kinase able to phosphorylate nucleolin specifically (Caizergues-Ferrer et al. 1987). To further characterize the Xenopus protein, we carried out a similar procedure on Xenopus hepatocytes. The two polypeptides of $M_{r}$ 95,000 and $M_{r} 90,000$ exhibited the same feature and were labeled with $\left[\gamma^{32} \mathrm{P}\right]$ ATP. A weak labeling of the $M_{x}$ 59,000 polypeptide was also observed (Fig. 2, lane 3).

To identify the nucleolin mRNA in Xenopus, Northern blotting was performed using the heterologous cDNA from hamster CHO cells as a probe (Lapeyre et al. 1985) (Fig 3). In RNA from CHO cells, the probe reveals an mRNA of $2.7 \mathrm{~kb}$ (Fig. 3, lane 1). When Xenopus oocyte RNA was probed, three major bands were detected (2.7 kb, $1.8 \mathrm{~kb}, 1.6 \mathrm{~kb}$ ) (Fig. 3, lane 2). Further use of a Xenopus nucleolin cDNA clone, as a probe on the same blot, showed that the major band of $2.7 \mathrm{~kb}$ represents nucleolin mRNA (Fig. 3, lane 2'). One of the related mRNA revealed by the $\mathrm{CHO}$ probe encodes another glycine-dimethylarginine-rich protein (to be published elsewhere). An additional minor band of $3.3 \mathrm{~kb}$ also reacted with the Xenopus cDNA probe. Further studies to identify the 3.3-kb mRNA are underway.

\section{Isolation and characterization of a cDNA specific for Xenopus nucleolin}

The hamster nucleolin cDNA was used as a probe to

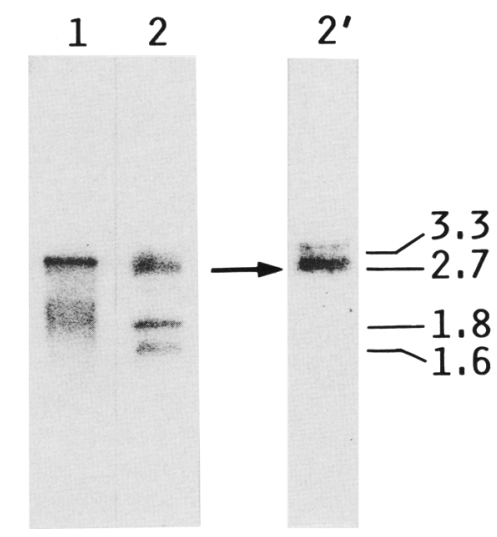

Figure 3. Northern blot analysis. RNA was isolated, separated under denaturing conditions in a formaldehyde $-1 \%$ agarose gel, blotted onto nitrocellulose filter, and then hybridized with different probes. CHO nucleolin cDNA was used to probe total RNA purified either from $\mathrm{CHO}$ cells as a control (lane 1) or from Xenopus oocytes (lane 2). Xenopus nucleolin cDNA was used to probe Xenopus oocyte RNA (lane 2'). screen a Xenopus oocyte cDNA library constructed in $\lambda$ gt 10 and kindly provided by D. Melton. Fifteen clones were isolated and characterization of five of them showed that they overlapped. The longest cDNA, pXomN1, was $2.1 \mathrm{~kb}$ long and was incomplete, lacking the $5^{\prime}$ terminus. From its sequence, the sequence of a peptide with 526 residues was deduced (Fig. 4), and a comparison with the 713 residues of the hamster nucleolin sequence (Lapeyre et al. 1987) showed unequivocally that pXom 1 encodes Xenopus nucleolin. However, we found that the different domains of the two proteins have undergone very different evolutionary constraints. For instance, two out of the three acidic domains located in the amino half of the protein are much shorter than in rodents, reduced from 25 and 33 contiguous acidic residues to 11 and 20, respectively. Even between different rodents, we have already found that this region is able to evolve very rapidly by replacement (Asp-Glu), deletion, or addition of residues (Lapeyre et al. 1985).

The carboxyl half of the protein contains four RNAbinding domains homologous to those of rodent nucleolin that have been shown to interact with ribosomal RNA (Bugler et al. 1987). The overall organization of the domains is conserved mainly, but two major observations can be made. First, the evolution of each domain is strikingly different between amphibian and rodent with a conservation of $42,52,65$, and $87 \%$ respectively from domain 1 to domain 4 , taking only the amino acids that are conserved strictly into account, and allowing some gaps to align the sequence (Fig. 5). The second remark concerns the comparison of the four domains with each other. For instance, in Xenopus domains 1 and 4 exhibit only $34 \%$ homology, which is less than the homology between the first two domains of Xenopus and rodent $(42 \%)$.

As opposed to the acidic domains, the carboxy-terminal glycine-rich domain is longer in Xenopus 161 amino acids) than in $\mathrm{CHO}$ (53 amino acids) or in mouse (49 amino acids). The overall composition is roughly conserved, except for the presence in Xenopus of two glutamine residues.

\section{Nucleolin mRNA accumulation during oogenesis and embryo development}

We have followed the accumulation of nucleolin mRNA and the fate of nucleolin during the course of oogenesis and embryogenesis to compare it with the known pattern of accumulation of two classes of ribosomal components, rRNA and r-proteins. The accumulation of nucleolin mRNA during oogenesis and embryogenesis has been analyzed by Northern blot or by RNA dot-blot hybridization. For quantitative data, we have used total RNA instead of poly(A) ${ }^{+}$RNA to avoid any loss of material during oligo(dT)-cellulose column purification. Figure 6 shows the accumulation of RNA during oogenesis and during embryo development. Nucleolin mRNA is accumulated very rapidly at the beginning of oogenesis, reaching the highest value at stage II, after 
which it decreases rapidly. This is quite similar to the expression of r-protein mRNAs except these were shown to decrease more slowly after stage II (Pierandrei-Amaldi et al. 1982). The 2.7-and 3.3-kb mRNAs behave similarly. After fertilization, all transcriptional activity is switched off. From the mid-blastula stage (stage 8)

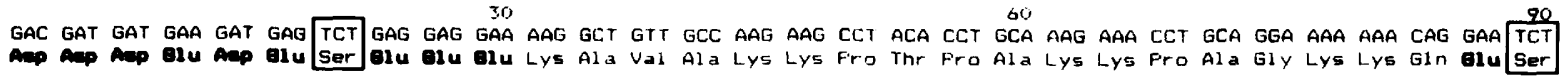

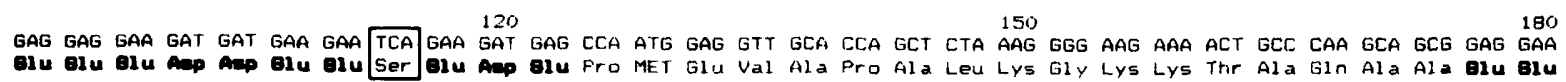
Blu elu blu Aap Aap Blu Blu Ser Blu Aap Blu fro MET Glu Val Ala Pro Ala Leu Lys Gly Lys Lys Thr Ala Gln Ala Ala Blu Blu GAT GAT GAG GAG GAG GAC GAT GAC GAT GAG GAA GAC GAT GAT GAT GAG GAG GAA CAG CAA GGC TCT GCA AAA CGC AAA AAA GAG ATG CAA

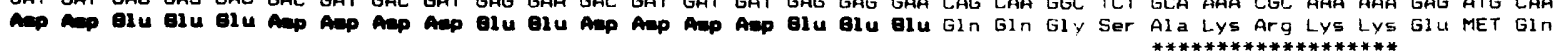
300 AAA ACA GAC ACT GCA TCA GAA GGC TTG TCA ATO TTT ATT GGE AAC TTA AAC TCT ACA AAG GAA AAA ACT ATC CTG AGG GCA AAA AAA ACA AAA ACA GAC ACT GCA TCA GAA GGC TTG TLA ATC TTT ATT GGE AAC TTA AAC TCT ACA AAG GAA Lys Thr Ile leu Arg Ala Lys Lys Thr Lys Thr Asp Thr Ala Ser GIu Gly Leu Ser Ile fine Ile Gly Asn Leu Asn Ser Thr Lys Glu ITT GAT GAA CTA AAA GAT GCT CTG AGG GAG TTC TTT TCA AAG AAG AAC CTA ACC ATA CAG GAC ATA AGE ATT GGA AAC TCA AAG AAG ITT Phe Asp Glu Leu Lys Asp Ala Leu Arg Giu phe Fhe Ser lys Lys Asn Leu thr Ile Gln Asp Ile Arg Ile gly Asn Ser Lya Lya Phe GGG TAT GTG GAT TTC TCA TCC GAG GAA GAO GTT GAG AAG GCT CTG AAA CTG ACT GGG AAG AAG ATA CIT GGT ACA GAG GTG AAG ATT GAA Bly Tyr Yel Aas Phe Ser Ser Glu Glu Glu Val Glu Lys Ala Leu Lys Leu Thr Giy Lys bys Ile Leu Gly Thr Glu Val Lys Ile Glu AAG GCT ATG GCT TTT GAC AAA AAC AAA ACT GCT GAA AAT AAG AAG GAG AGG GAT TCC CGA ACT CTG TTT GTG AAG AAC ATC CCC TAT AGC Lys Ala MET Ala Phe Asp Lys Asn Lys Thr Ala Glu Asn Lys Lys Gili Arg Asp Ser arg Thr Leu fhe Val Lys Asn Ile Pro Tyr Ser 210 ACA ACT GTT GAG GAG CTG CAG GAG ATA TTT GAA AAT GCT AAA GAT ATT AGA ATT CCC ACT GGC AAA GAT GGA TCA AAT AAA GGG ATT 720 Thr Thr Val Glu Glu Leu Gln Glu Ile phe Glu Asn Ala Lys Asp Ile Arg Ile Fro Thr Gly Lys Asp Gly Ser Aan Lys Gly Ile Ale TAT GIT GAA TIT AGC AAT GAA GAT GAG GCA AAC AAA GCT CTT GAA GAG AAG CAA GGA GCA GAG ATT GAG GGA CGC TCT ATT TTC GTT GAC Iyr Yel glu Phe Ser Asn glu Asp Glu Ala Asn Lys Ala Leu glu Glu Lys Gln Gly Ala Glu Ile Glu Gly Arg Ser Ile Phe Val Asp TTC ACT GGT GAA AAG AGC CAG AAT TCG GGA AAT AAA AAA GGA CCG CAA GGC GAT TCC AAG GTA CTT GTC GTA AAC AAC CTG TCA TAT AGT Phe Thr Gly Glu Lys Ser Gln Asn Ser Gly Asn Lys Lys Gly fro Gln Gly Asp Ser. Lys Val Leu Val Val Asn Asn Leu Ser Tyr Ser
Pli GCA ACA GAA GAC AGC CTC CGT GAA GTC TTT GAA AAA GCC ACA TCT ATA CGG ATA CCA CAG AAC CAG GGA CGG GCT AAG GGC TTT GCC TTT Ala Thr Glu Asp Ser Leu Arg Glu Val fhe Glu Lys Ala Thr Ser Ile Arg Ile Fro gln Asn Gin Gly AroAla Lye Gly phe Ala phe 330 ATT GAA TTC TCT TCT GCG GAA GAT GCA AAA GAT SCA ATG GAT TCT TGT AAC AAE ACA GAA ATT GAG GGA CGG TCC ATA CGG CTG GAG TTT

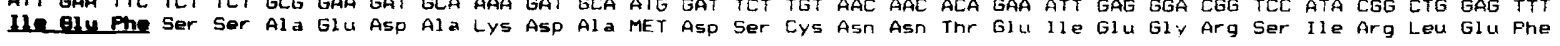
AGC CAA GGA GGT GGC CCT CAA GGT GGT GGA AGG GGA GGT TCA GCG CAG TCA AAA ACC CTC ITT GTC AGA GGT CTT TCT GAA GAC ACC ACT Ser Gln Gly Gly Gly fro Gln Gly Gly Gly Arg Gly Gly Ser Ala Gin Ser Lys Thr Leu fhe Val Arg Gly Leu Ser Glu Asp Thr Thr GAA GAA ACC TTG AAG GAA GCA TIT GAT GGC TCT GTT AAT GCC AGG ATT GTG ACG GAC AGA GAT ACT GGC GCA TCC AAG GGG TIT GGA TTT GAA GAA ACC TTG AAG GAA GCA TTT GAT GGC TCT GTT AAT GCC AGG ATT GTG ACG GAC AGA GAT ACT GGC GCA TCC AAG GGG TIT GGA TIT
Glu Glu Thr Leu Lys Glu Ala Phe Asp Gly Ser Val AST Ala Arg Ile Val Thr Asp Arg Asp Thr Gly Ale Ser Lye Gly phe Gly Phe GTA GAC TTT TCC ACT GCT GAA GAC GCT AAA GCT GCC AAA GAG GCC ATG GAG GAT GGG GAA ATT GAT GGA AAC AAA GTT ACT CTA GAC TIT Vel ane Phe Ser Thr Ala Glu Asp Ala Lys Ala Ala Lys Glu Ala MET Glu Asp Gly Glu Ile Asp Gly Ast Lys Val Thr Leu Asp fhe GCA AAA CCT AAA GGC GAG TCC CAG CGT GGA GGA CGT GGG GGT TTT GGL AGA GGA GGT 1410 GGE TTT AGA GGT GGT CGT GGT GGC AGA GGA GGT Ala Lys Pro Lys Gly Glu Ser Gln Arg Gly Gly Arg Gly Gly Phe Gly Arg Gly Gly Gly Phe Arg Gly Gly Arg Gly Gly Arg Gly Gly GGA GGA GGA AGA GGC. ITT GGT GGC AGA GGT GGT GGA CGC GGA AGA GGA GGA TTT GGA GGA AGA GGA GGT GGA GGA TIC AGA GGT GGT CAG Gly Gly Gly Arg Gly Phe Gly Gly Arg Gly Gly Gly Arg Gly Arg Gly Gly Phe Gly Gly Arg Gly Gly Gly Gly Phe Arg Gly Gly Gln 1560

GGC GGA GGA TTC AGA GGT GGT CAG GGC AAG AAG ATG AGG TTT GAT GAC TGA GCAGTTTTCATCTCCCCTTTAAACCTCAAGCCATCTCCCTGAAAGGACTCT

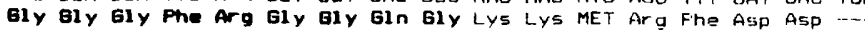
1650

1650
GGGGGCAGAAAGGGGATCTGGATTCCCTACCCCAAATAAATCTACTCTTGGCAGAGCCTTCTGTGTGGACATTCCAATGTGGAAATACATGTTTCCTGTATCACCTGGATTCCAAGTC 1750 30

\section{0}

$\underline{90}$

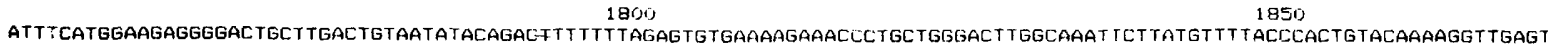

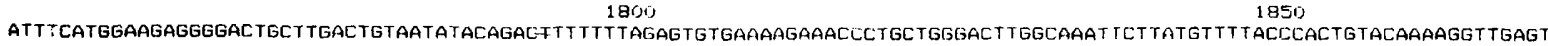
1900

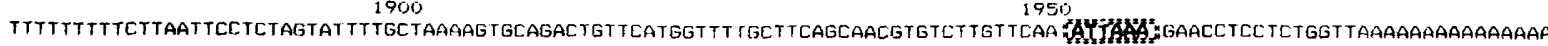
2000

AAAAAAAAAAAAAAAAAAAAAAAAAA

Figure 4. Xenopus nucleolin: pXomN1 DNA sequence and deduced amino acid sequence. Numbers above the DNA sequence refer to the nucleotides while numbers underlined on the right refer to the amino acid residues. Acidic tracts are in boldface type. The three serine residues that are candidates for the phosphorylation sites are boxed. The potential nuclear translocation signal, similar to the prototype signal of SV40 large T antigen (Kalderon et al. 1984) is underlined by stars. This signal is located just downstream from the last acidic stretch as in the Xenopus protein N038 (Schmidt-Zachmann et al. 1987). The four RNA-binding consensus sequences, centered on the residues at postions $149,238,327$, and 417 , are in boldface type and underlined. The glycine-rich domain at the carboxyl terminus is in boldface type. The polyadenylation signal is boxed. 


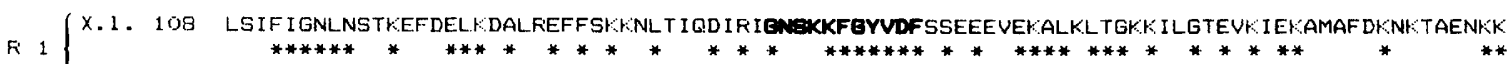

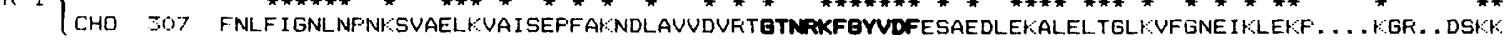

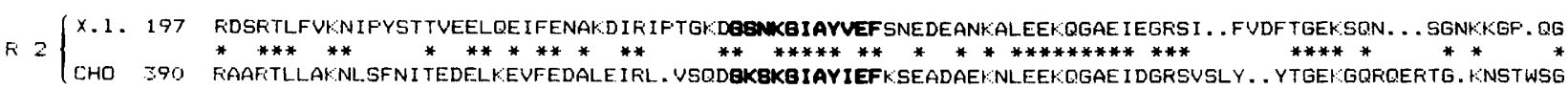

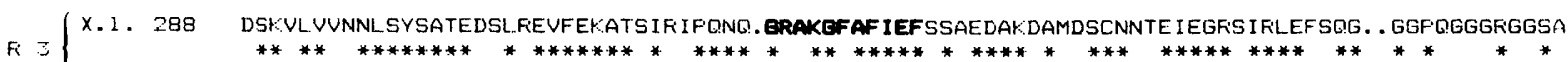

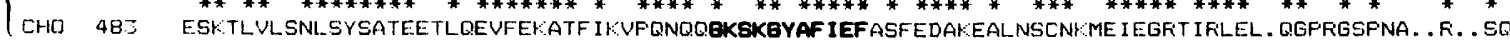

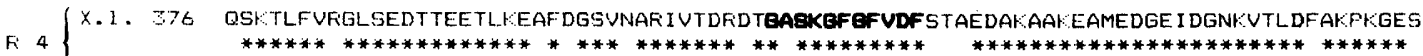

$$
\begin{aligned}
& \text { CHO } 569 \text { FSKTLFUKGLEEDTTEETLFESFEGSURARI UTDFIETBSBKEFGFVDFNSEEDAKAAKEAMEDGE IDGNKUTLDWAKFKISEG }
\end{aligned}
$$

Figure 5. Alignment of the four RNA-binding domains of Xenopus nucleolin with those of CHO nucleolin (R I to R IV). Numbers on the left refer to the position of the first residue of a line. The consensus sequence indentified previously is in boldface type. Sequences were aligned allowing some gaps (.) to get the best matches $(*)$.

a) Oocytes

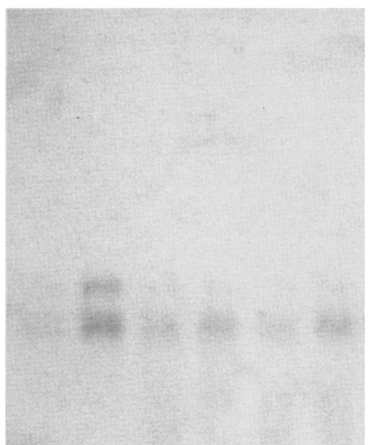

I II III IV $\mathrm{V}$ VI

\section{S t a g e s}

Figure 6. Northern blot showing nucleolin mRNA accumulation during oogenesis and embryogenesis. Total RNA corresponding to 0.5 oocyte or embryo was separated by electrophoresis in a denaturing formaldehyde-1\% agarose gel, blotted onto nitrocellulose filter, and hybridized under stringent conditions with nick-translated Xenopus nucleolin cDNA as a probe. (a) Stages I to VI of oogenesis according to Dumont 1972. Autoradiography was carried out for $20 \mathrm{hr}$ at $-70^{\circ} \mathrm{C}$, with an intensifying screen (XM film from $3 \mathrm{M}$ ). (b) Stages 3 to 40 of embryogenesis according to Nieuwkoop and Faber (1956). Autoradiography was carried out for $10 \mathrm{hr}$.

(Nieuwkoop and Faber 1956) there is a revival of transcription for a number of genes, including the nucleolin gene. In embryogenesis a strong increase in the $2.7-\mathrm{kb}$ nucleolin mRNA is observed at stage 14 while $3.3-\mathrm{kb}$ mRNA increases only slightly. We have studied the expression of nucleolin mRNA in comparison with the mRNAs of r-proteins S8 and L1, and with rRNA (Fig. 7A). Quantification of the results of several dot-blots and Northern hybridizations for nucleolin and r-protein is plotted in Figure 7B. Both nucleolin and r-protein mRNAs begin to be transcribed at roughly the same time, but the accumulation patterns are significantly different. As described already, r-protein mRNA synthesis appears after the mid-blastula transition, increases slowly up to around stage 40 , and decreases slightly at the end of embryogenesis (Pierandrei-Amaldi et al. 1982). Nucleolin mRNA increases very rapidly between stages 8 and 14, after which it remains at a constant level up to stage 37 and decreases slowly afterward. These results demonstrate that the accumulation of nucleolin mRNA anticipates both the accumulation of $r$ protein mRNA and the production of new ribosomes. The highest amount of nucleolin mRNA coincides with the reappearance of nucleoli after gastrula (Hay and Gurdon 1967).

\section{Polysome/mRNP distribution and translation of nucleolin mRNA in Xenopus embryos}

Having established that nucleolin mRNA is accumulated in embryos much more rapidly than r-protein mRNAs or rRNA, we have studied the fate of this mRNA by analyzing its distribution in polysomes and free mRNPs. It appears that, as early as stage 18 , about $60 \%$ of nucleolin mRNA is loaded onto polysomes, although only $25 \%$ of r-protein mRNAs are engaged. At stage $36,80 \%$ of nucleolin and $60 \%$ of r-protein S8 messages are translated. Therefore, nucleolin mRNA not only is accumulated before that of the r-proteins but also is used for translation earlier (Fig. 8).

Finally, we looked for the appearance of the protein during embryogenesis. At the end of oogenesis, we have shown that using the nucleolin antiserum on Western blots only the $M_{r} 59,000$ and $M_{r} 48,000$ polypeptides were detected (Fig. 2, lane 5). During embryogenesis (Fig. 9A), the two polypeptides of $M_{r} 95,000$ and $M_{r} 90,000$ were detected from stage 24 and present until stage 46 . It is even possible to detect nucleolin synthesis earlier, at stage 16 , by using its capacity for endogenous phosphorylation (Fig 9B). The $M_{r} 59,000$ peptide appears from stage 16 when a weak revival of rDNA gene transcription occurs, but it is particularly prominent at stage 32 and 38 when ribosome accumulation is very high (Pierandrei-Amaldi et al. 1982) and then decreases until stage 

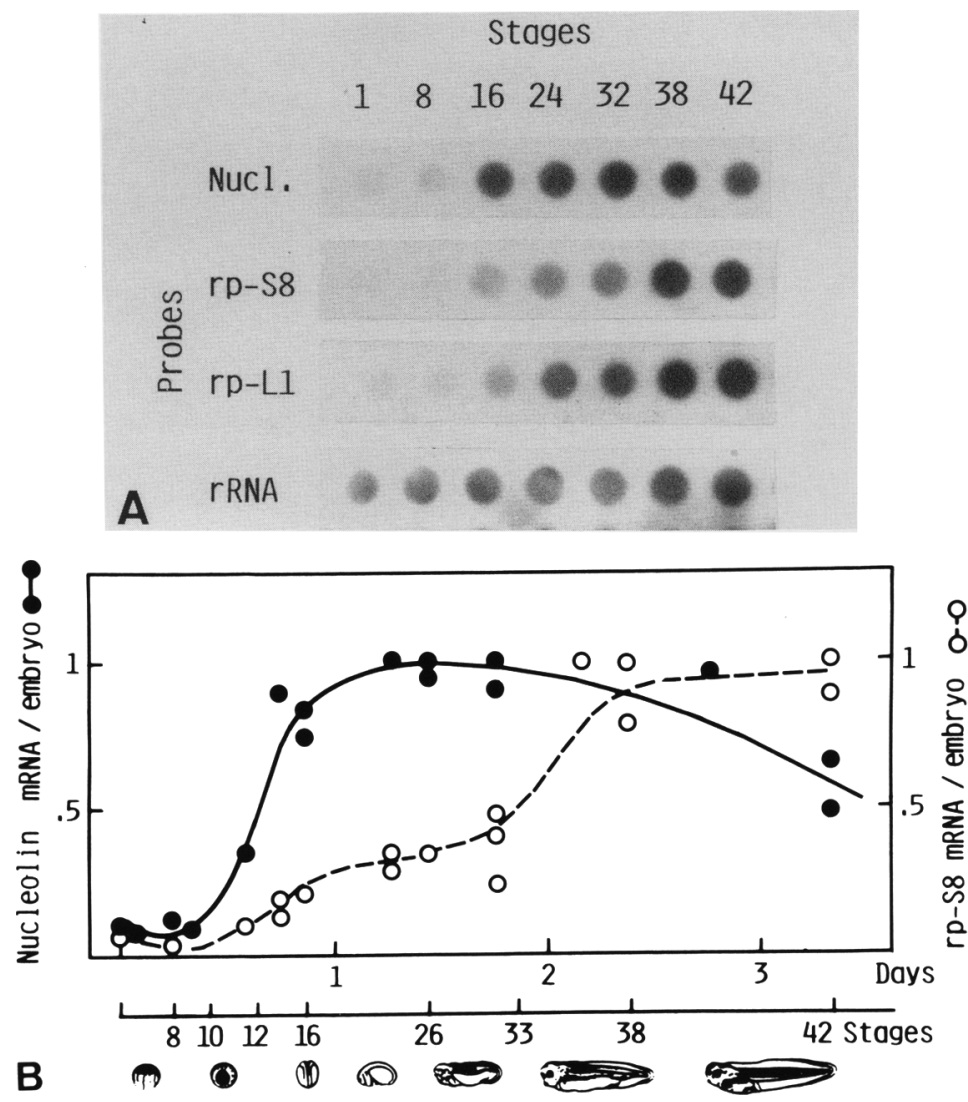

Figure 7. Relative expression of rRNA, nucleolin, and r-protein mRNAs during embryogenesis. (A) Total RNA corresponding to two embryos of each stage was analyzed by dot-blot and hybridization with different DNA probes: nucleolin (Nucl.), two r-proteins ( $r p$ - $S 8$ and $r p-L 1)$, and rDNA (rRNA). (B) Quantitative data were obtained for nucleolin and r-protein S8 by densitometric scanning of the autoradiograms, the values from four independent experiments have been plotted. Average values for each stage are expressed in percent of the value of the stage with the highest score. $\operatorname{rpS} 8 \mathrm{mRNA}(\mathrm{O}-\mathrm{O})$; nucleolin mRNA (-O).

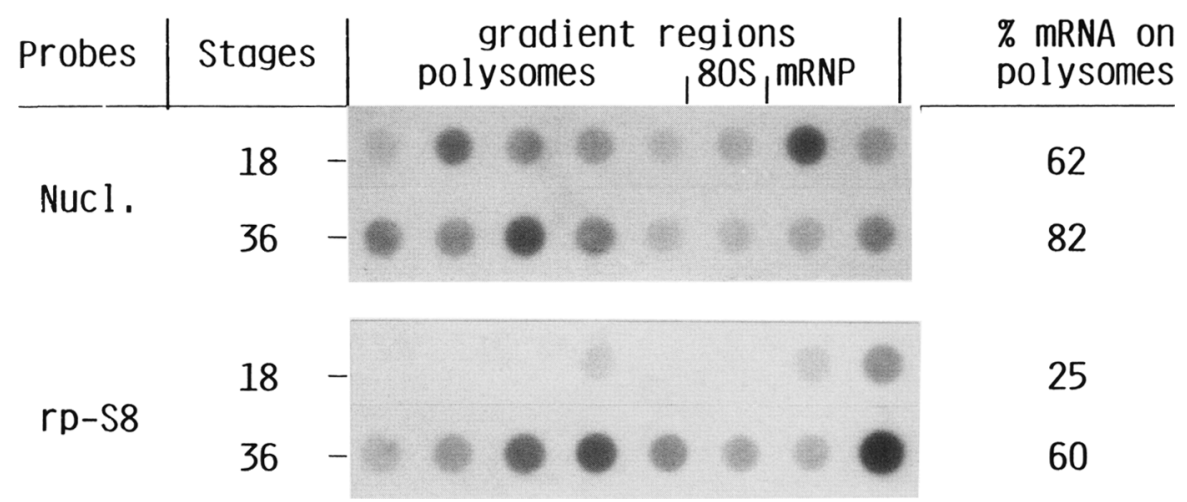

Figure 8. Polysome/mRNP distribution of nucleolin and r-protein mRNA. Cytoplasmic fractions of 15 embryos of stage 18 and 36 were run through sucrose gradients. RNA was extacted from gradient fractions and analyzed by dot-blot hybridization with probes for nucleolin, or for r-protein (S8) mRNA. The percent of mRNA in polysomal or mRNP fraction was determined by densitometric scanning of the autoradiogram. 


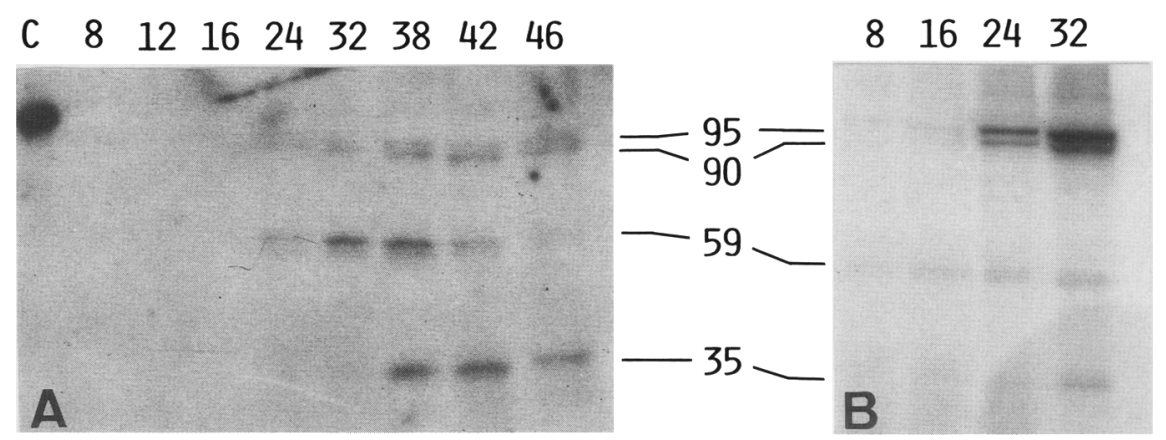

Figure 9. Fate of nucleolin during embryogenesis. Total protein extracts of 10 embryos were prepared in the presence of protease inhibitors as described in Materials and methods. $(A)$ Proteins corresponding to one embryo per lane were electrophoresed on a $10 \%$ SDS-PAGE. The amount of protein per lane increases from $10 \mu \mathrm{g}$ for stage 8 to $100 \mu \mathrm{g}$ at stage 46 . The gel was blotted onto nitrocellulose, probed with purified IgG directed against nucleolin of $\mathrm{CHO}$, then stained with ${ }^{125}$-labeled protein A. The filter was exposed for $20 \mathrm{hr}$ at $-70^{\circ} \mathrm{C}$ with an intensifying screen. Lanes: $(C)$ Control lane, $0.2 \mu \mathrm{g}$ of purified $\mathrm{CHO}$ nucleolin; (8-46) embryo stage according to Nieuwkoop and Faber (1956). (B) Endogenous phosphorylation of nucleolin in embryonic extracts. Same protein extracts as in $A$ were incubated in the presence of $\left[\gamma^{-32}\right.$ P]ATP. Proteins were separated on a $10 \%$ SDS-PAGE. The gel was dried and autoradiographed for $4 \mathrm{hr}$ at room temperature. (Lanes 8-32) Embryo stages. Numbers in the middle refer to the peptides in $\mathrm{kD}$.

46. Another peptide of $M_{r} 35,000$ that was not detected in oocytes is accumulated from stage 38 and remains constant up to stage 46.

\section{Discussion}

\section{Structure of nucleolin in $\mathrm{X}$. laevis}

Our results obtained with an antiserum against hamster nucleolin and with cDNA cloning show that a protein highly homologous to rodent nucleolin is present in $X$. laevis. The overall organization of the protein is essentially the same in Xenopus and in rodent, with three distinct domains: an acidic amino-terminal region, four RNA-binding domains, and a glycine-rich carboxyl terminus. Extended clusters of negatively charged amino acids are found to be responsible for the abnormal mobility of protein in SDS-PAGE (Kaufmann et al. 1984; Kleinschmidt et al. 1986). Since rodent nucleolin, $M_{r}$ 77,000 , migrates with an apparent molecular weight of 100,000 , we can deduce that the fewer acidic residues in Xenopus can reflect the difference in apparent molecular weight between rodent and amphibian. The presence of two molecular forms of $M_{r} 100,000$ and 95,000 was reported in rodent (Bourbon et al. 1983), and the $M_{r} 95,000$ and 90,000 polypeptides found in Xenopus could correspond to these. Similar acidic domains have been described already in other nuclear proteins: Xenopus nuclear protein NO38 (Schmidt-Zachmann et al. 1987), the karyophilic protein N1/N2 (Kleinschmidt et al. 1986), nucleoplasmin (Bürglin et al. 1987; Dingwall et al. 1987), the HMG 1 and 2 proteins (Walker 1982), and several other proteins (for review, see Earnshaw 1987). Nucleoplasmin and protein N1/N2 are involved in nucleosome assembly (Dilworth et al. 1987), although, on the contrary, we have shown that nucleolin can induce chromatin decondensation by displacement of histone H1 (Erard et al. 1988), as can also be achieved by HMG 1 or 2 proteins. In both cases, polyacidic stretches are the obvious candidates for histone binding. These stretches could also be involved in preribosome formation by interacting with positively charged ribosomal proteins. Indeed, nucleolin that is already bound to the pre-rRNA (see below) could neutralize the charge of ribosomal proteins, allowing them to associate in nascent preribosomes.

The mechanism of specific RNA sequence recognition by nucleolin is still an open question. We have found, both in vivo and in vitro (Bourbon et al. 1988b), that nucleolin interacts with three different classes of sites along the pre-rRNA molecule, according to their binding affinities. Some of these sites, located in $18 \mathrm{~S}$ and in $28 \mathrm{~S}$ RNAs, correspond to very well conserved sequences, while others, located for example in the external spacer, exhibit very poor conservation between different species. Thus, a major point to address is to know how the four RNA-binding blocks work. A first hypothesis is that they act in an independent manner with, for instance, the strongly conserved fourth block interacting with a well-conserved sequence in $18 \mathrm{~S}$, although the less-conserved first block that has evolved very rapidly could recognize variable sequences in the external spacer and reflect the coordinated evolution of both the protein and of the target RNA. A second hypothesis could be that the four blocks work in a coordinate manner with all of them involved in each interaction, the most conserved responsible for the specificity of recognition while the others would only cooperate, with a decreasing specificity from the third to the first domain. In vitro studies using the different RNA-binding domains produced by genetic engineering and synthetic RNAs are in progress to test these hypotheses.

The long, flexible, glycine-rich domain is conserved roughly between rodents and Xenopus. This sequence is also found in fibrillarin, a nucleolar protein which is associated with U3 RNA (Lischwe et al. 1985), and also in different hnRNPs (Chung and Wooley 1986; Cobianchi 
et al. 1986). This domain could be involved in RNA binding through dimethylarginine residues or, by analogy with keratin and intermediate filaments, be involved in protein-protein interactions (Fisher et al. 1986). Nucleolin and fibrillarin that are both present in the prenucleolar bodies (Gas et al. 1985; Benavente et al. 1987) could interact either together or with other proteins and play a role in nucleolar reformation.

\section{Nucleolin is involved in the first steps of ribosome biogenesis}

In Xenopus oocytes, after rDNA amplification, a large number of nucleoli is formed (400 to 2500 per oocyte), followed by a huge accumulation of ribosomes from stage III. Nucleolin mRNA is accumulated in stage II, but the nucleolin detectable in earlier oocytes appears to be matured rapidly to smaller polypeptides of $M_{r} 59,000$ and 48,000 . We interpret these results as indicating a concomitant and related maturation of nucleolin with the transcription of rDNA. This is in agreement with our previous results obtained in vitro when studying transcription in isolated nucleoli. Nucleolin acts as an inhibitor of pre-rRNA synthesis when its proteolysis is inhibited. In the absence of a protease inhibitor, maturation of phosphorylated nucleolin occurs and transcription of rDNA is allowed (Bouche et al. 1984). Maturation of nucleolin also has been observed under other physiological conditions: (1) phosphorylation of nucleolar protein in rat ventral prostate is stimulated after testosterone or polyamine treatment and is followed by an increased degradation of nucleolin to a $M_{r} 59,000$ peptide (Suzuki et al. 1985); (2) hyperphosphorylation of a $M_{x}$ 60,000 peptide structurally and immunologically related to nucleolin appears after tumor promoter treatment of human fibroblast (Issenger et al. 1988). In vitro maturation of nucleolin has been described that results in peptides of $M_{r} 95,000,70,000$ and 60,000 in CHO cells (Bourbon et al. 1983) and in a $M_{r} 48,000$ peptide in calf thymus (Sapp et al. 1986).

After oocyte maturation the germinal vesicle breaks down and the extra nucleoli vanish. Then, from midblastula transition, nucleolin mRNA is accumulated and recruited onto polysomes more efficiently than $r$ protein mRNAs. Nevertheless, an increased recruitment of both mRNAs onto polysomes between the neurula and tailbud stages suggests the existence of a translational control, similar to the one described for r-proteins (Pierandrei-Amaldi et al. 1985). Nucleolin protein is detected as early as stage 16 when the nucleoli reform; its accumulation precedes $r$-protein synthesis and ribosome accumulation, known to become very active after the tailbud stage (stage 26). From this stage, nucleolin begins to mature and smaller peptides that react with the antiserum are detected in later embryonic stages. These results, along with our in vitro experiments, suggest that in vivo nucleolin is somehow involved in the preparation and/or preliminary steps of ribosome synthesis.

The results reported here support the notion that nu- cleolin performs vital functions in ribosome biogenesis, via different domains within the protein molecule. Furthermore, we present evidence that the maturation of nucleolin is linked closely to these functions.

\section{Materials and methods}

\section{Biological materials}

$X$. laevis were purchased from Fisch Hoeck, South Africa, or from SEREA, CNRS, France. Oocytes were separated manually into six stages according to Dumont (1972) and staging of embryos was according to Nieuwkoop and Faber (1956).

\section{Cell fractionation}

$X$. laevis hepatocyte nuclei were purified as described previously (Mathieu et al. 1975). For polysome purification, 15 embryos from each stage were homogenized in $0.5 \mathrm{ml}$ of $10 \mathrm{mM}$ Tris-Cl ( $\mathrm{pH} 7.4$ ), $150 \mathrm{mM} \mathrm{KCl}, 4 \mathrm{~mm} \mathrm{MgCl}_{2}, 0.05 \%$ Triton $\mathrm{X}-100$. The cytoplasmic extracts were loaded onto $15-50 \% \mathrm{su}$ crose gradients. Centrifugation was performed on a Spinco centrifuge with a SW41 rotor for $2 \mathrm{hr}$ at 37,000 rpm. Gradient fractions were ethanol precipitated overnight at $-20^{\circ} \mathrm{C}$, and the RNA was extracted from the precipitates (Pierandrei-Amaldi et al. 1982).

\section{Immunofluorescence microscopy}

Isolated liver nuclei were cytocentrifuged onto polylysinecoated microscope slides. They were fixed with $4 \%$ paraformaldehyde in phosphate buffer (pH 7.2) for $15 \mathrm{~min}$. After washing, nuclei were processed for immunofluorescence microscopy as described previously (Gas et al. 1985). Small pieces of ovaries were removed and fixed as above. After washing, samples were quick-frozen in isopentane cooled with liquid nitrogen. Cryostat sections of $12-\mu \mathrm{m}$ thickness were air-dried and processed for immunofluorescence as above.

\section{Protein analysis}

Low ionic strength extracts of Xenopus hepatocyte nuclei were purified as described previously (Bourbon et al. 1983). Protein extracts from one to ten oocytes or embryos were homogeneized in 50 to $100 \mu \mathrm{l}$ of $10 \mathrm{~mm}$ Tris- $\mathrm{Cl}(\mathrm{pH} 7.6), 50 \mathrm{mM} \mathrm{NaCl}, 2$ $\mathrm{mM}$ EDTA and $5 \mu \mathrm{g} / \mathrm{ml}$ leupeptin, $5 \mu \mathrm{g} / \mathrm{ml}$ aprotinin, $2 \mu \mathrm{g} / \mathrm{ml}$ pepstatin, $10 \mathrm{mM}$ benzamidine- $\mathrm{Cl}, 1 \mathrm{~mm}$ phenylmethylsulfonyl-fluoride (PMSF) as protease inhibitors. After a 30-min RNase B treatment $(100 \mu \mathrm{g} / \mathrm{ml})$, yolk and lipids were removed by two cycles of centrifugation at $10,000 \mathrm{~g}$ for $10 \mathrm{~min}$ at $4^{\circ} \mathrm{C}$. Proteins were precipitated by ammonium sulfate: nucleolin and related peptides precipitate between 40 and $80 \%$ of saturation. Protein molecular weight markers were obtained from BioRad. Proteins were separated on $10 \%$ SDS-PAGE according to Laemmli (1970). Proteins were transferred to nitrocellulose by electroblotting using a BioRad apparatus in $25 \mathrm{~mm}$ Tris, 192 mM glycine, $0.1 \%$ SDS, $20 \%$ methanol $(\mathrm{pH} 8)$ for $2 \mathrm{hr}$ at $60 \mathrm{~V}$ $(0.3 \mathrm{~A})$ at $4^{\circ} \mathrm{C}$. For immunostaining of the Western blot, we used a protocol described previously (Lapeyre et al. 1985).

\section{RNA analysis}

Total RNA from oocytes or embryos, or RNA from the polysomal fraction was extracted according to Probst et al. (1979) and analyzed either by dot-blot or Northern hybridization as 
described previously (Pierandrei-Amaldi et al. 1982). The ${ }^{32}$ P-labeled DNA probes were obtained by nick-translation. Prehybridization and hybridization were performed in $50 \%$ formamide at $42^{\circ} \mathrm{C}$ as described by Thomas (1980). Filters were then washed with two changes of $2 \times$ SSC, $0.1 \%$ SDS at room temperature and two changes of $0.1 \times \mathrm{SSC}, 0.1 \%$ SDS at $48^{\circ} \mathrm{C}$ and exposed to X-ray film.

\section{Quantification of autoradiograms}

LKB Ultroscan XL laser was used for densitometric analysis of $\mathrm{X}$-ray film of RNA dot blot and Northern blots.

\section{Screening of the cDNA bank, subcloning, and sequencing}

A cDNA bank constructed by D. Melton in $\lambda$ gt 10 with poly(a) ${ }^{+}$ RNA from Xenopus oocytes was screened using the insert of plasmid BL16.2 (Lapeyre et al. 1985) as a specific probe for nucleolin. The isolated recombinant phages were characterized and inserts were subcloned in PTZ 19R. Nucleotide sequencing was performed according to Maxam and Gilbert (1980) with the addition of a T-specific reaction (Rubin and Schmid 1980) or using the dideoxy chain termination method of Sanger et al. (1977). DNA sequence was determined on both strands and across most restriction sites used as initiation points.

\section{Acknowledgments}

We are grateful to J. Feliu for technical assistance in DNA sequencing, to B. Stevens for comments and criticism of the manuscript, to H.M. Bourbon, M.T. Carri, and L. Montesano for fruitful discussion, and to A.M. Duprat and co-workers for their help in Xenopus maintenance and for providing some biological materials.

This work was supported by grants from Centre National de la Recherche Scientifique, Association pour le Developpement de la Recherche sur le Cancer, Progetto finalizzato Ingeneria Genetica e basi moleculari delle malattie ereditatie, CNR, and Ministero della Pubblica Istruzione.

During this work, M.C-F. was a recipient of a one-year EMBO fellowship to work in Dr. Amaldi's laboratory in Rome.

\section{Note}

Sequence data described in this paper have been submitted to the EMBL/GenBank Data Libraries.

\section{References}

Benavente, R., K.M. Rose, G. Reimer, B. Hügle-Dörr, and U. Scheer. 1987. Inhibition of nucleolar reformation after microinjection of antibodies to RNA polymerase I into mitotic cells. J. Cell Biol. 105: 1483-1491.

Bouche, G., M. Caizergues-Ferrer, B. Bugler, and F. Amalric. 1984. Interrelations between the maturation of a $100 \mathrm{kD}$ nucleolar protein and pre rRNA synthesis in $\mathrm{CHO}$ cells. Nucleic Acids Res. 12: 3025-3035.

Bouche, G., N. Gas, H. Prats, V. Baldin, J.-P. Tauber, J. Teissié, and F. Amalric. 1987. Basic fibroblast growth factor enters the nucleolus and stimulates the transcription of ribosomal genes in ABAE cells undergoing G0-G1 transition. Proc. Natl. Acad. Sci. 84: 6770-6774.

Bourbon, H.M., B. Bugler, M. Caizergues-Ferrer, F. Amalric, and J.P. Zalta. 1983. Maturation of a $100 \mathrm{kDa}$ protein associated with preribosomes in CHO cells. Mol. Biol. Rep. 9: 39-47.
Bourbon, H.M., B. Lapeyre, and F. Amalric. 1988a. Structure of the mouse nucleolin gene: The complete sequence reveals that each RNA binding domain is encoded by two independent exons. I. Mol. Biol. 200: 627-638.

Bourbon, H.M., B. Bugler, and C. Mathieu. 1988b. Nucleolin, a RNA binding protein involved in biosynthesis of preribosomes in eukaryotes. I. Cell. Biochem. UCLA Symp. 404: 37 .

Bugler, B., M. Caizergues-Ferrer, G. Bouche, H. Bourbon, and F. Amalric. 1982. Detection and localization of a class of proteins immunologically related to a $100 \mathrm{kD}$ nucleolar protein. Eur. J. Biochem. 128: 475-480.

Bugler, B., H.M. Bourbon, B. Lapeyre, M.O. Wallace, J.H. Chang, F. Amalric, and M.O.J. Olson. 1987. RNA binding fragments from nucleolin contain the ribonucleoprotein consensus sequence. J. Biol. Chem. 262: 10922-10925.

Bürglin, T.R., I.W. Mattaj, D. Newmeyer, R. Zeller, and E.M. De Robertis. 1987. Cloning of nucleoplasmin from Xenopus laevis and analysis of its developmental expression. Genes Dev. 1: 97-107.

Busby, S.J. and R.H. Reeder. 1982. Fate of amplified nucleoli in Xenopus laevis embryos. Dev. Biol. 91: 458-467.

Caizergues-Ferrer, M., F. Dousseau, N. Gas, G. Bouche, B. Stevens, and F. Amalric. 1984. Induction of new proteins in the nuclear matrix of $\mathrm{CHO}$ cells by a heat shock: Detection of a specific set in the nucleolar matrix. Biochem. Biophys. Res. Commun. 118: 444-450.

Caizergues-Ferrer M., P. Belenguer, B. Lapeyre, F. Amalric M.O. Wallace, and M.O.J. Olson. 1987. Phosphorylation of nucleolin by a nucleolar type NII protein kinase. Biochemistry 26: 7876-7883.

Chung, S.Y. and J. Wooley. 1986. Set of novel, conserved proteins fold pre-messenger RNA into ribonucleosomes. Proteins 1: 195-210.

Cobianchi, F., D.N. SenGupta, B.Z. Zmudzka, and S.H. Wilson. 1986. Structure of rodent helix-stabilizing protein revealed by cDNA cloning. J. Biol. Chem. 261: 3636-3543.

Davidson, E.H. 1986. Gene activity in early development 3rd edition, pp. 160-163. Academic Press, New York.

Dilworth, S.M., S.J. Black, and R.A. Laskey. 1987. Two complexes that contain histones are required for nucleosomes assembly in vitro. Role of nucleoplasmin and $\mathrm{N} 1$ in Xenopus egg extracts. Cell 51: 1009-1018.

Dingwall, C., S.M. Dilworth, S.J. Black, S.E. Kearsey, L.S. Cox and R.A. Laskey. 1987. Nucleoplasmin cDNA sequence reveals polyglutamic acid tracts and a cluster of sequences homologous to putative nuclear localization signals. $E M B O \mathrm{I}$. 6: $69-74$.

Dumont, J.N. 1972. Oogenesis in Xenopus laevis. J. Morphol. 136: $153-179$.

Earnshaw, W.C. 1987. Anionic regions of nuclear proteins. I. Cell Biol. 105: 1479-1482.

Erard M., P. Belenguer, M. Caizergues-Ferrer, A. Pantaloni, and F. Amalric. 1988. A major nucleolar protein, nucleolin, induces chromatin decondensation by binding of hisotne $\mathrm{H}$. Eur. J. Biochem. 175: 525-530.

Escande-Géraud, M.L., M.C. Azum, J.L. Tichadou, and N. Gas. 1985. Correlation between rDNA transcription and distribution of a $100 \mathrm{kDa}$ nucleolar protein in CHO cell. Exp. Cell Res. 161: 353-363.

Fisher, D.Z., N. Chaudhary, and G. Blobel. 1986. cDNA sequencing of nuclear lamin $A$ and $C$ reveals primary and secondary structural homology to intermediate filament proteins. Proc. Natl. Acad. Sci. 83: 6450-6454.

Gas, N., M.L. Escande, and B. Stevens. 1985. Immunolocalization of $100 \mathrm{kDa}$ nucleolar protein during the mitotic cycle in 
CHO cells. Biol. Cell 53: 209-218.

Hadjiolov, A.A. 1985. The nucleolus and ribosome biogenesis. In Cell biology monographs, vol. 12, pp. 133-165. Springer, New York.

Hay, E. and J.B. Gurdon. 1967. Fine structure of the nucleolus in normal and mutant Xenopus embryos. I. Cell Sci. 2: 151167.

Herrera, A. and M.O.J. Olson. 1986. Association of protein C23 with rapidly labeled nucleolar RNA. Biochemistry 25: 6258-6264.

Issenger, O.G., T. Martin, W.W. Richter, M.O.J. Olson, and H. Fujiki. 1988. Hyperphosphorylation of N-60, a protein structurally and immunologically related to nucleolin after tumour promoter treatment. EMBO I. 7: 1621-1626.

Kalderon, D., B.L. Roberts, W.D. Richardson, and A.E. Smith. 1984. A short aminoacid sequence able to specify nuclear location. Cell 39: 499-509.

Kaufmann, E., N. Geisler, and K. Weber. 1984. SDS-PAGE strongly overestimates the molecular masses of the neurofilament proteins. FEBS Lett. 170: 81-84.

Kleinschmidt, J.A., C. Dingwall, G. Maier, and W. Franke. 1986. Molecular characterization of a karyophilic histone binding protein: cDNA cloning, aminoacid sequence and expression of nuclear protein N1/N2 of Xenopus laevis. EMBO J. 5: 3547-3552.

Laemmli, U.K. 1970. Cleavage of structural protein during the assembly of the head of bacteriophage T4. Nature 256: 680685.

Lapeyre B., M. Caizergues-Ferrer, G. Bouche, and F. Amalric. 1985. Cloning of cDNA encoding a $100 \mathrm{kDa}$ nucleolar protein (nucleolin) of Chinese hamster ovary cells. Nucleic Acids Res. 13: 5805-5816.

Lapeyre, B., F. Amalric, S.H. Ghaffari, S.V. Venkatarama Rao, T.S. Dumbar, and M.O.J. Olson. 1986. Protein and cDNA sequence of a glycine-rich dimethylarginine containing region located near the carboxyl-terminal end of nucleolin. $J$. Biol. Chem. 261: 9167-9173.

Lapeyre, B., H.M. Bourbon, and F. Amalric. 1987. Nucleolin, the major nucleolar protein of growing eukaryotic cells. An unusual protein structure revealed by nucleotide sequence. Proc. Natl. Acad. Sci. 84: 1472-1476.

Lischwe, M., R. Reddy, R. Cook, L. Yeoman, E. Tan, M. Reichlin, and H. Busch. 1985. Purification and partial characterization of a nucleolar scleroderma antigen ( $\mathrm{Mr} 34,000$; pl, 8.5) rich in dimethylarginine. I. Biol. Chem. 260: 1430414310.

Mathieu, C., A.-M. Duprat, M.H. Dupuy, P. Ferrer, J.-P. Zalta, and J.C. Beetschen. 1975. Effets biologiques de solution de protéines chromatiniennes non histones sur un système embryonnaire en différenciation in vitro. J. Embryol. Exp. Morphol. 33: 1051-1066.

Maxam, A.M. and W. Gilbert. 1980. Sequencing end labeled DNA with base specific chemical cleavages. Methods Enzymol. 65: 499-560.

Nieuwkoop, P.D. and J. Faber. 1956. Normal table of Xenopus laevis (Daudin). North Holland, Amsterdam.

Ochs, R.L., M.A. Lischwe, E. Shen, R.E. Carroll, and H. Busch. 1985. Nucleologenesis: Composition and fate of prenucleolar bodies. Chromosoma 92: 330-336.

Olson, M.O.J. and B.A. Thomson. 1983. Distribution of proteins among chromatin components of nucleoli. Biochemistry 22: 3187-3193.

Orrick, L., M.O.J. Olson, and H. Busch. 1973. Comparison of nucleolar proteins of normal rat liver and Novikoff hepatoma ascites cells by two dimensional polyacrylamide gel electrophoresis. Proc. Natl. Acad. Sci. 70: 1316-1320.
Pfeifle, J. and F. Anderer. 1983. Localization of phosphoprotein PP 105 in cell lines of various species. Biochem. Biophys. Res. Commun. 116: 106-112.

Pierandrei-Amaldi, P., N. Campioni, E. Beccari, I. Bozzoni, and F. Amaldi. 1982. Expression of ribosomal-protein genes in Xenopus laevis development. Cell 30: 163-171.

Pierandrei-Amaldi, P., E. Beccari, I. Bozzoni, and F. Amaldi. 1985. Ribosomal production in normal and anucleolate Xenopus embryos: Regulation at the posttranscriptional and translation levels. Cell 42: 317-323.

Probst, E., A. Kressmann, and M. Birnstiel. 1979. Expression of sea urchin histone genes in the oocyte of Xenopus laevis. $J$. Mol. Biol. 135: 709-732.

Rubin, C.M. and C.W. Schmid. 1980. Pyrimidine specific chemical reactions useful for DNA sequencing. Nucleic Acids Res. 8: 4613-4619.

Sanger, F., S. Nicklen, and A.R. Coulson. 1977. DNA sequencing with chain-termination inhibitors. Proc. Natl. Acad. Sci. 74: 5463-5467.

Sapp, M., R. Knippers, and Z. Richter. 1986. DNA binding properties of a $110 \mathrm{kDa}$ nucleolar protein. Nucleic Acids Res. 14: $6803-6820$.

Schmidt-Zachmann, M.S., B. Hügle-Dorr, and W.W. Franke. 1987. A constitutive nucleolar protein identified as a member of the nucleoplasmin family. EMBO J. 6: 18811890.

Suzuki, N., H. Matsui, and T. Hosoya. 1985. Effects of androgen and polyamines on the phosphorylation of nucleolar proteins from rat ventral prostates with particular reference to a 110-kDa phosphoprotein. J. Biol. Chem. 260: 8050-8055.

Thomas, P.S. 1980. Hybridization of dentured RNA and small DNA fragments transferred to nitrocellulose. Proc. Natl. Acad. Sci. 77: 5201-5205.

Walker, J.M. 1982. Primary structures In The HMG chromo somal proteins. (ed. E.W. Johns), pp. 69-87. Academic Press, London. 


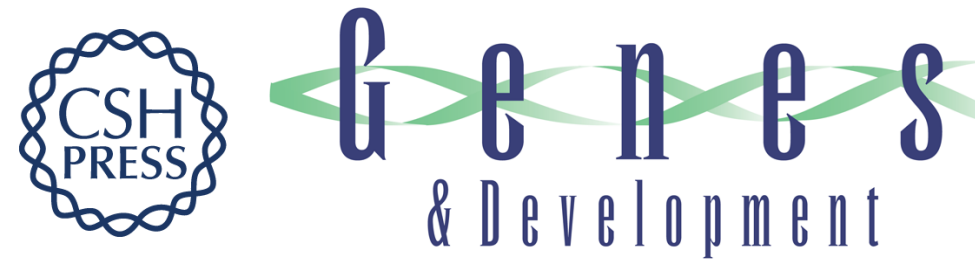

\section{Nucleolin from Xenopus laevis: cDNA cloning and expression during development.}

M Caizergues-Ferrer, P Mariottini, C Curie, et al.

Genes Dev. 1989, 3:

Access the most recent version at doi:10.1101/gad.3.3.324

References This article cites 48 articles, 14 of which can be accessed free at:

http://genesdev.cshlp.org/content/3/3/324.full.html\#ref-list-1

License

Email Alerting

Service

Receive free email alerts when new articles cite this article - sign up in the box at the top right corner of the article or click here.

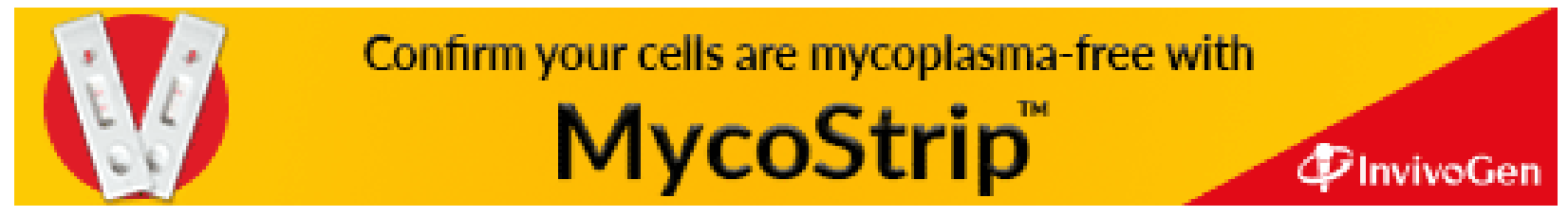

